Patrícia T. R. Lucchese 1

\title{
Eqüidade na gestão descentralizada do SU S: desafios para a redução de desigualdades em saúde
}

\author{
Equity in decentralized management of the SUS: \\ reducing health inequalities - the challenges
}

1 Departamento de Ciências Sociais, ENSP, Fiocruz. Av. Leopoldo Bulhões 1480 , 9o andar 21041-210, M anguinhos Rio de Janeiro RJ. lucchese@ensp.fiocruz.br
Abstract In public debate on the health sector, the subject of health equity has come to prominence as a goal to be achieved in decentralising the U nified H ealth System (SU S) in order to improve health conditions throughout Brazil for the population as a whole. The debate is al ready considerably complicated by the need for a precise definition of the concept of equity, evidencing the complexity of the environment in which the public task of reducing inter-regional inequalities is to be performed in a context of interaction and interdependence among world and national economic, social and cultural processes, which pressure government agendas in these times of globalisation. $0 n$ the basis of (1) a specific interpretation of the concept of equity in decentralised management of theSU S; (2) a current reconsideration of certain proposals for social management that feature in international development debate; and (3) a review of certain authors' theoretical contributions with regard to State action in this heterogeneous and contradictory environment undergoing extensive mutation, this article endeavours to systematise some of the challenges and questions posed in order for health to be managed publicly with a view to equity in the Federative Republic of Brazil.

Key words Equity, Public management, Development, D ecentralisation, $\mathrm{H}$ ealth policy
Resumo 0 tema da eqüidade em saú de vem ganhando destaque no debate público setorial como objetivo a se alcançar na gestão descentralizada do Sistema Ú nico de Saúde para a efetiva melhoria das condições de saúde do conjunto da população brasileira em todo o território nacional. Este debate, já bastante difícil pela necessidade de se precisar o conceito de eqüidade, evidencia a complexidade do ambiente em que se processam as tarefas públicas para a redução de desigualdades inter-regionais, no contexto de interação einterdependência entre processos econômicos, sociais e culturais, mundiais e nacionais, que pressionam as agendas governamentais nestes tempos de globalização. Esteartigo empreen de um esforço de si stematização de alguns dos desafios e indagações colocados para uma gestão pública da saúde orientada à eqüidade na República Federativa do Brasil, a partir de uma interpretação própria para o conceito de eqüidadena gestão descentralizada do SUS, da atualização de algumas proposi ções para a gestão social em discussão no debate internacional sobre o desenvolvimento, e da revisão da contribuição teórica de alguns autores sobre a ação do Estado neste ambiente heterogêneo e contraditório de grandes mutações.

Palavras-chave Eqüidade, Gestão pública, D esenvolvimento, Descentralização, Política de saúde 


\section{As mudanças recentes na gestão pública da saúde no Brasil}

A operacionalização das diretrizes constitucionais de descentralização e de participação social ("da comunidade") para a organização e gestão do Sistema Ú nico de Saúde (SUS) vem produzindo expressivas mudanças no desenho institucional da ação governamental e, não seria exagero dizer, profundas modificações no modo de atuação do Estado brasileiro no campo social.

Tais mudanças relacionam-se, em primeiro lugar, à instituição de processos de deliberação democrática na gestão setorial, tais como 1) a real ização de Conferências de Saúde, com representação dos vários segmentos sociais, para a proposição de diretrizes para a política de saúde, 2) a institucionalização dos Conselhos de Saúde como órgãos colegiados permanentes e de caráter deliberativo sobre a política de saúde; e 3) a criação das Comissões Intergestores, nas esferas federal e estadual, como fóruns de negociação e pactuação entre os gestores das três instâncias de direção do SUS para o gerenciamento do processo de descentralização.

De outra perspectiva, as mudanças refletem-se no progressivo fortalecimento das esferas subnacionais de governo e no estabelecimento de novas relações intergovernamentais: 1) na gestão pública do cuidado à saúde; 2) na operacionalização gradativa de suas novas atribuições e competências legais; e 3) na definição de suas responsabilidades específicas no âmbito das estratégias nacionais de descentralização e reorganização da atenção à saúde por meio de Normas Operacionais Básicas do SU S editadas pelo M inistério da Saúde.

Destaca-se também a crescente autonomia e independência dos entes federados subnacionais na gestão política e financeira dos sistemas locais a partir das crescentes parcelas de recursos federais transferidas direta e automaticamente do Fundo Nacional de Saúde para os Fundos Estaduais e M unicipais. E, mais recentemente, com a definição de um patamar para a aplicação de recursos dos orçamentos públicos (U nião, estados e municípios) no financiamento das ações e serviços de saúde, conforme estabeleceu a Emenda Constitucional n. 29 (EC 29), promulgada em setembro de 2000.

A definição de diretrizes para a regulamentação das alterações constitucionais aprovadas naEC 29 vem acumulando novos consensos não apenas quanto ao conjunto de ações e serviços públicos identificados como de responsabilida- de estatal e ao nível de comprometimento de cada esfera político-administrativa no financiamento das despesas del es decorrentes, mas também quanto aos instrumentos de acompanhamento, fiscalização e controle dos recursos aplicados na gestão da política setorial. N esse caso, o processo de formação de consensos conta com a representação de instituições e órgãos dos poderes executivo, legislativo e judiciário: M inistério da Saúde, CONASS, CONASEM S, Consel ho Nacional de Saúde, tribunais de contas da U nião, dos estados e dos municípios, e M inistério Público (Brasil, 2002).

Pode-se considerar, assim, que as condições políticas, institucionais, jurídicas e financeiras construídas em doze anos de implementação do SUS, vêm contribuindo significativamente para o estabelecimento de caminhos promissores para a consolidação de uma gestão descentralizada e participativa do sistema e da política de saúde e para uma maior governabilidade setorial na garantia do direito à saúde.

No entanto, ao quetudo indica, tais mudanças ainda não resultaram em redução substantiva das desigualdades em saúde no país. Estudos recentes evidenciam a persistência, ao final dos anos 90 , de importantes iniqüidades relacionadas 1) à distribuiç̧ão espacial da oferta de recursos humanos e de capacidade instalada; 2) ao acesso e utilização de serviços (públicos e privados); 3) à qualidade da atenção recebida; e 4) às condições de vida e de saúde da população nas diferentes localidades (Duarte, 2000; Viana et al., 2001; M ello Jorge, Gotlieb \& Laurenti, 2001; Araújo, 2001; Duarte et al., 2002).

0 acompanhamento dos debates ocorridos na Comissão Intergestores Tripartite nos últimos anos, no âmbito do Projeto Descentralização On Line (http://www.ensp.fiocruz.br/ descentralizar), e os resultados de pesquisa recém-concluída sobre as desigualdades intra e inter-regionais no ambiente de gestão pública da saúde, confirmam tal constatação (Lucchese et al., 2002). As diferentes condições demográficas, epidemiológicas, socioeconômicas, assistenciais, gerenciais e financeiras nos estados e regiões geram distintos perfis de problemas, dificuldades e prioridades no espaço local e regional de intervenção setorial e produzem desigualdades relevantes na capacidade de o Sistema Ú nico de Saúde responder às necessidades locais.

Dessa forma, diante da urgência de se reduzir as desigualdades na capacidade de resposta do sistema, o tema da eqüidade em saúde ganha força no debate setorial como objetivo a se al- 
cançar para a efetiva melhoria das condições de saúde do conjunto da população brasileira em todo o território nacional.

Abordar a eqüidade nesse novo contexto da gestão da política de saúde e do Sistema Ú nico de Saúde não é tarefa fácil porque exige um esforço de reflexão que reconheça o "clima e o terreno" do novo ambiente de gestão descentralizada em que se processam as tarefas públicas. Este esforço requer uma revisão conceitual que não somente aperfeiçoe o já avançado mapeamento das desigualdades no país, como simultaneamente auxilie na identificação das tarefas de gestão necessárias para reduzi-las.

Este artigo, em caráter exploratório, empreende um primeiro esforço de reflexão nessa direção. Tomando como referência o trabalho conceitual desenvolvido por Amartya Sen, no seu livro A desigualdade reexaminada (2001), publicado originalmente em 1992, econsiderando a complexidade do ambiente em que se processam as tarefas de gestão pública hoje no mundo, e em particular na América Latina, identificam-se al gumas tarefas prioritárias para a redução das desigual dades em saúde no Brasil, para as quais a gestão do SU S deve se capacitar.

\section{0 conceito de eqüidade na gestão descentralizada do SUS}

Encontrar a interpretação do conceito de eqüidade mais adequada ao campo de atuação em saúde para então operacionalizá-lo em tarefas de gestão do sistema orientadas à redução de desigualdades é um grande desafio. Como bem lembra Duarte (2000), as opções conceituais, inerentes aos desenhos de sistemas de saúde, orientam a escolha dos critérios distributivos, a escolha de indicadores a utilizar para avaliar 0 grau de eqüidade e a interpretação dos resultados em relação à efetividade das interven ções.

A literatura internacional vem adotando como ponto de partida para novas definições do conceito de eqüidade em saúde aquele desenvolvido por Whitehead (1992), segundo o qual eqüidade implica que ideal mente todos deveriam ter a justa oportunidade de obter seu pleno potencial de saúde e ninguém deveria ficar em desvantagem de alcançar o seu potencial, se isso puder ser evitado.

Em recente trabalho, o Center for $\mathrm{H}$ ealth Equity, Training, Research and Evaluation CHETRE (2000) apresenta uma boa síntese conceitual desenvolvida a partir da definição de
Whitehead (1992). Segundo o CHETRE, o conceito de eqüidade sugere que pessoas diferentes deveriam ter acesso a recursos de saúde suficientes para suas necessidades de saúde e que o nível de saúde observado entre pessoas diferentes não deve ser influenciado por fatores além do seu controle. Como conseqüência, a iniqüidade ocorre quando diferentes grupos, definidos por suas características sociais e demográficas como, por exemplo, renda, educação, ou etnia, têm acesso diferenciado a serviços de saúde ou diferenças nas condições de saúde (health status). Essas diferenças são consideradas iníquas se elas ocorrem porque as pessoas têm escolhas limitadas, acesso a mais ou menos recursos para saúde ou exposição a fatores que afetam a saúde, resultantes de diferenças que expressam desigual dades injustas (Chetre, 2000).

Tal concepção se adapta perfeitamente ao campo de preocupações individuais e sociais relacionadas à saúde. Apresenta, no entanto, dificuldades para sua operacionalização em tarefas de gestão. Em primeiro lugar, ao conceito de necessi dade de saúde, bastante determinado cultural mente e variado quando relacionado às atividades do cotidiano, à experiência da dor, à morbidade, à longevidade, às possibilidades de acesso ao cuidado, entre outros aspectos, correspondem diferentes expectativas quanto aos recursos de saúde necessários para atendê-las e sua suficiência. Acrescente-se a isso, a dificuldade de se discriminar o que é necessidade de saúde diante da pressão e do fascínio que o complexo médico industrial, cada vez mais diverso, tecnologicamente sofisticado e dinâmico, exerce sobre o imaginário de potenciais usuáriose dos profissionais de saúde.

Em segundo lugar, porque tal concepção impõe qualificar e selecionar entre as diversase extremas desigualdades sociais e econômicas, que afetam direta ou indiretamente a saúde em contextos como o brasileiro, aquelas diferenças desnecessárias e injustas.

Para contornar essas dificuldades e tentar o peracionalizar tarefas de gestão orientadas à eqüidade, um bom caminho a seguir parece ser a "perspectiva da capacidade" desenvolvida por Sen (2001) em seu brilhante reexame das desigualdades e dos ordenamentos sociais em geral no início dos anos 90. Diante do reconhecimento da heterogeneidade básica dos seres humanos e da multiplicidade de variáveis em cujos termos a igual dade pode ser julgada - o que não raro resulta em divergências relevantes de avaliação - o autor propõe como ponto de partida 
para a análise da desigual dade a seguinte indagação: "está se buscando igual dade de quê?".

Segundo a perspectiva desenvolvida pelo autor, o estudo da realização e avaliação individual e social de bem-estar nas sociedades contemporâneas deve deslocar o foco dos instrumentos/meios tradicionalmente utilizados para comparação, como por exemplo, domínio sobre bens primários, recursos ou renda real, para os seus elementos constitutivos, quais sejam, os "funcionamentos" necessários ao alcance de bem-estar, isto é, estados e ações inter-relacionados (beings and doings) ea "capacidade" de realizar tais funcionamentos a partir de oportunidades reais.

Por exemplo, os funcionamentos relevantes para a realização de uma pessoa podem variar desde coisas elementares como estar nutrido adequadamente, estar em boa saúde, livre de doenças que podem ser evitadas e da morte prematura etc., até realizações mais complexas, tais como ser feliz, ter respeito próprio, tomar parte da vida na comunidade, e assim por diante (Sen, 2001). Ou seja, os funcionamentos são constitutivos do estado de uma pessoa. A capacidade corresponde às ações livremente escolhidas pelas pessoas para realizar tais funcionamentos.

A desigualdade deve ser examinada, assim, a partir da maior ou menor capacidade de escoIha - entendida em sua interação com as oportunidades reais - , entre alternativas possíveis para a realização de bem-estar no conjunto de funcionamentos que o constituem e viabilizam. Em suma, esta abordagem aponta para a necessidade de se examinar a liberdade para realizar em geral, e a capacidade para realizar funcionamentos em particular.

A partir dessa perspectiva, bastante resumida no esforço de reflexão aqui empreendido, Sen (2001) analisa ainda as implicações que tal formulação traz para a estimativa da liberdade e vantagem individual, para teorias da justiça, para a economia do bem-estar, para a teoria da avaliação da desigual dade, para a estimativa da pobreza tanto em países ricos como em pobrese para a análise de desigualdades associadas a categorias como classe, sexo e outros grupos.

0 caminho traçado pelo autor, embora situado no campo de interfaces entre a ética, a economia e a filosofia política, constitui uma boa referência para uma mudança de foco da análise sobre as desigualdades econômicas e sociais que visem à formulação e implementação de políticas públicas orientadas à eqüidade no campo da saúde.
Escorel (2001) ressalta a pertinência de se abordar as desigual dades sociais no Brasil a partir da perspectiva desenvolvida por Sen (2001). Segundo a autora, para a reversão das condições atuais, para a elaboração de políticas eqüitativas dirigidas aos grupos social e economicamente mais vulneráveis, para os brasileiros que menos chances têm de desenvolver suas capacidades e potencialidades, ao invés de reduzir a elaboração das políticas aos fatores contingenciais da factibilidade financeira, há que se partir de um diagnóstico da pobreza como privação das capacidades, para então estabelecer o que deve ser feito $\mathrm{e}$ daí o que pode ser feito a cada momento (Escorel, 2001).

0 que parece promissor "tomar emprestado" a esta perspectiva de análise das desigualdades é a aplicação dos conceitos de "funcionamentos" e "capacidades", relacionados por Sen aos indivíduos, aos espaços de gestão descentralizada do SUS. N esse sentido, reconhecendo a priori a heterogeneidade básica entre municípios, estados e regiões do país, propõe-se, por analogia, deslocar o ponto de partida analítico dos funcionamentos e capacidades individuais necessários para assegurar a todos a liberdade de realização da saúde para alcançar bem-estar, para o dos funcionamentos e capacidades políticos, institucionais e administrativos necessários para assegurar aos espaços de gestão pública do SUS a liberdade de agir visando à realização da saúde dos indivíduos e o bem-estar da coletividade.

Entendendo-se a gestão pública como o espaço de tomada de decisões a partir da mediação entre as necessidades/demandas sociais e a administração dos recursos governamentais disponíveis, caberia, portanto, explorar o conceito de eqüidade na gestão descentralizada do SUS como a igualdade de condiç̧̃es e oportunidades, entre todas as unidades político-administrativas da Federação Brasileira, para a realização dos "funcionamentos" e para o desenvolvimento das "capacidades" necessárias à organização e implementação de respostas eficazes aos principais problemas que afetam a população em cada local.

Antes de tentar identificar quais seriam esses funcionamentos e capacidades, entretanto, é preciso compreender o ambiente complexo em que se realizam as tarefas de gestão pública do cuidado à saúde. 


\section{A complexidade do ambiente em que se processam as tarefas públicas}

Os dilemas colocados na atualidade pelo processo de globalização e pelo esgotamento dos modelos macroeconômicos de gestão e explicação da realidade social, trazem para o centro do debate público sobre o desenvolvimento humano, social e econômico a questão do papel do Estado no campo social e seu redesenho institucional e gerencial para uma performance efetiva na redução de desigualdades econômicas e sociais.

Nesse contexto proliferam iniciativas nacionais e internacionais, governamentais e não-governamentais, e novas linhas de reflexão e ação social que objetivam transformar positivamente o Estado na direção da eqüidade.

Esse cenário vem colocando novos e maiores desafios não apenas para a organização e eficiência da gestão pública em geral, e do cuidado à saúde, em particular, mas principalmente para que as tarefas públicas no campo social logrem modificar as situações de extrema desigualdade, cada vez mais evidentes.

Grande parte desses desafios, internacionalmente reconhecidos, vem sendo sistematizadas no âmbito das atividades do sistema das $\mathrm{N}$ ações Unidas (http://www.un.org) e na literatura recente de análise da crise e reforma do Estado M oderno, Providência Nacional - e do contrato social (Kliksberg, 1998; Santos, 1998, 2002; Rosanvallo, 1998; Castel, 1998; Vieira, 2001). Principalmente porque atravessam as agendas governamentais nacionais, pressionando pela renovação das tarefas públicas.

No plano da cooperação internacional para o desenvolvimento sustentável, a movimentação intelectual em torno da elaboração e implementação da Agenda 21 das Nações U nidas vem estabelecendo, desde o início dos anos 90, novos princípios e compromissos governamentais e intergovernamentais. Adotan do uma nova racionalidade ecológica voltada para a eficiência econômica, a eqüidade e a responsabilidade social, e objetivando enfrentar as disparidades internacionais e nacionais relacionadas à pobreza, à fome, às doenças e ao analfabetismo, e especialmente à deterioração dos ecossistemas, esses novos compromissos incluem: 1) o aperfeiçoamento dos processos de tomada de decisão e dos sistemas de planejamento e gestão, com vistas à articulação gradual das questões econômicas, sociais e de meio ambiente; 2) a institucionalização de sistemas de informação para a vigi lância e avaliação dos progressos alcançados; e 3) a adoção de estratégia nacional de desenvolvimento sustentável (UM, 2000).

0 Programa de Desenvolvimento das $\mathrm{Na}$ ções U nidas, em seu recente Relatório do Desenvolvimento Humano "Deepening Democracy at the Global Level" (UNDP, 2002), amplia o campo de mudanças necessárias para um desenvolvimento social eeconômico eqüitativo, ao se preocupar em salvaguardar a liberdade e dignidade de todos. Segundo o relatório, a democracia deve alargar-se e aprofundar-se por meio de instituições públicas sólidas e políticas públicas democráticas. Para tanto, identifica como requisitos fundamentais: a melhor atuação dos partidos políticos; eleições livres e justas, com sufrágio universal; a separação dos poderes, com braços independentes judiciais e legislativos; uma sociedade civil vibrante apta a monitorar o governo e os negócios privados; uma mídia independente e o controle civil sobre os militares; novas formas de participação da população no debate público e em atividades de ação coletiva.

Destaca, além disso, que dado o contexto mundial de interdependência e integração econômica, o aprofundamento da democracia impõe também a participação nas decisões globais que interferem diretamente nas regras e movimentos dos atores locais.

Dessa forma, ao incorporar os temas da globalização, da eficiência e eficácia governamental, da democracia, da governança e da responsabilização das instituições democráticas, o debate internacional estabelece novas tarefas políticas e institucionais para o alcance de eqüidade.

Tomando como referência as novas tendências e suas implicações para a reforma do Estado, Kliksberg (1998), em trabalho elaborado como tema central para uma reunião mundial de peritos em administração pública organizada pelas $\mathrm{N}$ ações U nidas, dá ênfase às inovações organizacionais para o redesenho do Estado no campo social. Segundo ele, um dos principais desafios para o estabelecimento de um desenvolvimento social ativo, eqüitativo e sustentado, consiste na reconstrução da capacidade de gestão estatal, a partir de um estilo gerencial adaptativo, estritamente conectado com a realidade e capaz de reagir ao andamento das variações contextuais.

0 autor identifica as seguintes linhas de trabal ho como chaves para a abertura de uma nova agenda para a atualização da gestão social: 
a) o reposicionamento organizacional da política social no campo de decisão sobre os temas de grande impacto social, visando assegurar a grande conciliação do econômico com o social; b) a melhoria radical da coordenação intraEstado por meio da integração operacional das diversas áreas em um desenho organizativo que facilite o cruzamento de enfoques, o trabal ho em equipe e a otimização conjunta dos escassos recursos disponíveis;

c) a descentralização dos serviços sociais para as regiões e municípios como condição para a integração regional de políticas econômicas e sociais e oportunidade para uma maior ef etividade, eficiência gerencial e sustentabilidade dos programas governamentais;

d) o desenvolvimento de meta-redes, convocadas pelo Estado, como meio de potencializar e complementar a contribuição de todos os atores sociais por meio da coordenação de ações conjuntas;

e) a adoção de desenhos participativos na programação, gestão e avaliação de programas de saúde, educação, habitação, desenvolvimento rural, nutrição, etc., para o alcance de benefícios gerenciais concretos; e

f) a melhoria da qualidade dos serviços públicos com a participação dos beneficiários/ usuários.

De uma perspectiva mais ampla, Santos (1998) ao discutir a crise do contrato social da modernidade e os impactos da globalização nas estruturas e práticas nacionais e locais, amplia o campo de desafios com que se depara a gestão pública, ao chamar a atenção para a urgência de se estabelecer, nesse ambiente heterogêneo e contraditório de grandes mutações, um novo modo de regulação social, fundado em processos de deliberação democrática e em uma nova institucionalidade compatível com um Estado articulador, integrador e coordenador de um conjunto híbrido de fluxos, redes e organizações em que se combinam e interpenetram elementos estatais e não estatais, nacionais e globais (Santos, 1998).

Considerando a emergência dessa nova forma de organização política mais vasta que o Estado, a disseminação de sociabilidades alternativas e a necessidade de se reinventar a democracia, Santos (1998) sugere que o Estado deve transformar-se num campo de experimentação, no qual diferentes soluções institucionais se desenvolvam com igualdade de oportunidades, de maneira que a prestação de bens públicos se dê sob várias formas, e que a opção entre elas ocor- ra somente após a avaliação de sua eficácia e qualidade democráticas por parte dos cidadãos. Essa experimentação, entretanto, não deve permitir que a incoerência, a instabilidade e a fragmentação estatal gerem exclusões. Ao contrário, deve garantir padrões mínimos de inclusão, que tornem possível a cidadania ativa necessária para o monitoramento, acompanhamento e avaliação do desempenho de projetos alternativos.

Vale mencionar, por fim, nessa breve referência ao debate teórico, a importância de se examinar com vagar, para uma melhor compreensão da extensão e profundidade das mudanças em curso que impõem a recomposição das políticas econômicas e sociais, as contribuições de Rosanvallon (1998), Castel (1998); Vieira (2001) e Zaluar (1997). Esses autores realizam, a partir da abordagem à crise do Estado Providência e dos Estados N acionais, e ao conceito de exclusão, um trabalho fundamental de revisão e análise da "questão social", no novo contexto global de ressignificação dos pactos de solidariedade, de trabalho, de cidadania, dos circuitos de reciprocidade, dos valores e métodos do "progresso social", e suas implicações para as políticas públicas e para a fundação de um novo espaço público.

A produção teórica desses autores oferece vigorosas linhas de reflexão para uma transformação positiva da regulação social na direção da democratização da sociedade, do Estado e da economia, e para a renovação organizacional, gerencial e política da gestão estatal.

Todas essas agendas, com vários pontos de conexão eáreas de interface, dão a dimensão da complexidade do ambiente de gestão pública na atualidade. Embora longe de estarem implementadas na maioria dos países, integram, sem dúvida, o campo de proposições dos diferentes atores e orientam várias inovações no âmbito das reformas nacionais, com impactos diretos nos processos de gestão estatal.

Parece lícito afirmar ainda que as idéias, proposições, consensos e dissensos difundidos nesse amplo debate integram as agendas específicas das diferentes áreas de ação social do Estado e pressionam por mudanças efetivas nos padrões tradicionais de gestão pública para que os resultados de suas ações promovam uma distribuição mais justa dos benefícios e serviços sociais, capazes de gerar mel horias significativas nas condições de vida de todos.

No campo da saúde, o reconhecimento da complexidade das interações necessárias para a produção social de bem-estar não é novo. As 
conexões entre ambiente e saúde, espaço e desigualdades, política e democracia, recursos e tecnologias para a atualização das práticas de cuidado à saúde apenas acrescentam mais desafios para uma gestão pública setorial orientada a melhorias permanentes na atuação dos sistemas de saúde, com impacto sobre a eqüidade sanitária.

Esta complexidade está bem retratada, por exemplo, no panorama apresentado no informe produzido pelo secretário-geral da O rganização M undial de Saúde em 2001 para o comitê preparatório da Cúpula M undial sobre Desenvolvimento Sustentável (Naciones U nidas, 2001):

M uchos de los principales factores que determinan los estados de salud y de enfermedad - así como las soluciones correspondientes - no dependen directamente del sector de la salud sino que se relacionan con el medio ambiente, el abastecimiento de agua y el saneamiento, la agricultura, la educación, el empleo, los medios de vida urbanos y rurales, el comercio, el turismo, la energía y la vivienda. Es indispensable abordar los factores implícitos que determinan la salud a fin de poder mejorar los sistemas de salud a largo plazo de forma perdurable y alcanzar un desarrollo ecológicamente sostenible. Se han registrado progresos en cuanto a forjar vínculos más estrechos entre el sector de la salud y otros sectores, en particular mediante planes nacionales y locales intersectoriales (salud y desarrollo) y el uso más intensivo de instrumentos de planificación como los procedimientos de evaluación de las consecuencias para la salud, los sistemas integrados de observación y vigilancia e indicadores y sistemas de información afinados. (Naciones U nidas, Consejo Económico y Social, 2001).

Consenso semelhante está na origem das formulações do movimento internacional pela Promoção da Saúde, que desde a sua 1a Conferência Internacional em 1986 vem disseminando iniciativas de elaboração de políticas públicas saudáveis, de criação de ambientes favoráveis à saúde, de reforço à ação comunitária, de desenvolvimento de habilidades pessoais e de reorganização dos serviços sanitários, com impacto na proposição e aperfeiçoamento de estratégias nacionais de aproximação intersetorial, de participação social e de reorganização do modelo de atenção à saúde (Gentile, 2001).

Especialmente nos espaços de gestão das cidades, várias experiências de articulação de ações intersetoriais em prol da saúde, de mobilização e partici pação comunitárias para a defesa e garantia de um ambiente saudável, de ha- bilitação das pessoas para a adoção de estilos de vida que preservem a sua saúde, de redefinição do modelo de atenção, em particular no que se refere à atenção básica, demonstram a pertinência de se consolidar o compromisso público, governamental e social, com a tarefa coletiva de promover a saúde das populações.

Nesse âmbito, de acordo com Gentile (2001) o estabelecimento de projetos ou estratégias nacionais têm demandado: 1) o aumento dos investimentos públicos para fomentar a saúde; 2) o fortalecimento e expansão de parcerias; 3) 0 aumento da capacidade comunitária para identificar e propor soluções para os seus problemas; 4) a garantia de direitos aos indivíduos; e 5) infra-estrutura para o desenvolvimento de inovações e atividades que promovam a saúde.

Em suma, o ambiente de gestão pública do cuidado à saúde pode ser caracterizado hoje como um vasto campo de reflexões, proposições e mudanças que buscam informar ou organizar intervenções públicas com impacto positivo sobre a eqüidade.

N esse ambiente, traduzir os objetivos e inovações para uma efetiva redução de desigualdades em saúde em tarefas concretas de gestão que modifiquem para melhor as condições de vida daqueles em situação menos favorecida, no mais curto prazo, permanece um grande desafio.

Tais tarefas, considerando a intensa interdependência entre os processos econômicos, sociais e culturais de caráter mundial e aqueles de caráter nacional ou regional na conformação das agendas governamentais, devem considerar a diversidade de respostas necessárias e adequadas a cada realidade, tanto no que diz respeito a modelos macroeconômicos quanto a inovações institucionais no campo da intervenção estatal.

\section{A descentralização como oportunidade para a maior eqüidade em saúde na América Latina}

Estudos recentes sobre as experiências latinoamericanas têm demonstrado que o alcance da eqüidade na gestão de serviços sociais na maioria dos países da região depende de três requisitos conjugados: 1) um sistema de financiamento estável orientado à eqüidade inter-regional; 2) um sistema de gestão flexível, com margens suficientes de autonomia local na administração dos recursos e da força de trabalho; e 3) a responsabilização das autoridades por seus re- 
sultados, a partir da efetiva delegação da gestão dos serviços aos governos subnacionais (Cepal, 2000).

Segundo o documento Equidad, desarrollo y ciudadania elaborado pela Comissão Econômica para a América Latina e o Caribe (Cepal, 2000), das N ações Unidas, a descentralização da gestão pública tem representado uma grande oportunidade para a adequação dos programas governamentais às demandas e singularidades locais e para um aumento da eficiência do gasto público, da eficácia gerencial, da sustentabilidade e da eqüidade no que se refere aos resultados da ação governamental, com potencial de assegurar maior efetividade ao gasto social.

A partir da análise dos objetivos, de aspectos fiscais e de organização institucional, e da participação social nos processos de descentralização dos serviços sociais em oito países latino-americanos, entre os quais o Brasil, a comissão identifica os seguintes desafios para uma gestão pública orientada à eqüidade, com base nas lições aprendidas:

- a clara definição das funções de coordenação, gestão do financiamento, provisão das prestações sociais e desenho e aplicação de normas reguladoras, que considerem as capacidades presentes e potenciais das regi ões;

- a descentralização do modelo de financiamento e das decisões sobre recursos humanos;

- o fortalecimento da competência técnica dos órgãos subnacionais para que possam assumir suas novas atribuições;

- a compatibilização entre as dimensões setorial e territorial na estrutura descentralizada; - o fortalecimento da competência técnica da gestão administrativa e financeira;

- a superação da fragmentação das responsabilidades quanto ao financiamento e à superposição de âmbitos de regulação e supervisão local e nacional;

- a superação da excessiva complexidade do financiamento, tanto no que diz respeito à diversidade das fontes de recursos, quanto à rigidez do destino e dos objetivos a elas fixados;

- melhores escalas econômicas e técnicas para a prestação de serviços sociais não necessariamente coincidentes com as repartições administrativas;

- maior autonomia de gestão das unidades que prestam serviços;

- o estabelecimento de um adequado sistema de informação, que permita dar seguimento e avaliar as transferências intergovernamentais e em geral, 0 avanço das metas fixadas;
- o incremento das receitas fiscais e o aumento da capacidade de arrecadação dos governos locais.

De fato, esses desafios presentes na gestão descentralizada dos serviços sociais na América Latina, com a complexidade que assumem em tempos de globalização, de mudanças no modo de regulação social e de redesenho institucional do Estado, integram, desdeo início dos anos 90, a agenda política setorial no Brasil. E éa partir desses desafios que se desdobram tarefas de gestão para a redução de desigualdades em saúde no país.

\section{Os funcionamentos e capacidades ne- cessários à gestão do SU S para a redução de desigualdades em saúde}

Tomando como referência o debate internacional, as contribuições de Kliksberg (1998) e Santos (1998), e retomando a "perspectiva da capacidade" desenvolvida por Sen (2001), conforme as adaptações sugeridas neste artigo, pode-se proceder a uma primeira aproximação aos "funcionamentos e capacidades" necessários à gestão descentralizada do SUS para que todas as unidades político-administrativas da República Federativa do Brasil tenham iguais condições e oportunidades de organizar respostas eficazes aos problemas de saúde no território nacional.

De imediato, alguns requisitos políticos, institucionais eadministrativos parecem ser decisivos para dar sustentabilidade a processos de gestão orientados à eqüidade. Entre eles, destacam-se:

- o alargamento dos padrões de inclusão social da política de saúde e a recusa à geração de novas exclusões, paralelamente ao desenvolvimento de vínculos mais concretos entre os diferentes atores sociais nos espaços de gestão, para a sua efetiva participação na formulação, acompanhamento, monitoramento e avaliação de desempenho de políticas e projetos al ternativos;

- a democratização das tarefas de coordenação dos divergentes, e muitas vezes contraditórios, interesses presentes no processo decisório setorial, e o fortalecimento de processos orgânicos de negociação que explicitem os conflitos reais subjacentes entre os diferentes atores; - a articulação intersetorial e a integração regional das políticas públicas na definição de uma agenda governamental que harmonize interven ções econômicas, sociais e ambientais de impacto sobre a eqüidade em saúde; 
- a atualização das funções públicas de plane jamento, regulação, financiamento e prestação de serviços, visando ao aperfeiçoamento institucional e organizacional do sistema de saúde para melhor assegurar a qualidade da atenção a todo e qualquer cidadão brasileiro.

Esses requisitos, que em seus resultados podem contribuir para instituições públicas mais sólidas e democráticas, representam condições essenciais para que a sociedade brasileira proceda a uma análise criteriosa de al gumas dimensões constitutivas do "estado" atual da gestão do sistema e busque identificar os "funcionamentos e capacidades" necessários para a efetiva redução de desigualdades em saúde no Brasil.

Como contribuição ao debate, este artigo encerra-se com algumas indagações e considerações finais.

- Como identificar e reduzir desigualdades a partir do tratamento simétrico dispensado historicamente pela direção nacional do sistema de saúde à totalidade de municípios, estados ou regiões, supondo sua homogeneidade quanto à situação demográfica, epidemiológica, socioeconômica, assistencial, gerencial e financeira, e ao perfil e magnitude dos problemas a enfrentar?

- Como identificar e reduzir desigualdades a partir da (re) programação de ações e serviços baseados em uma oferta mal distribuída de procedimentos médicos, equipamentos e tecnologias, historicamente estruturada a partir de interesses tão pouco sintonizados com as necessidades de saúde da população e com as necessidades das realidades locais?

- Como identificar e reduzir desigualdades a partir da ação de secretarias estaduais e municipais "desfinanciadas", com recursos humanos desval orizados (em todos os sentidos) e uma "pseudo-administração burocrática" incapaz de garantir padrões mínimos de eficiência para 0 alcance permanente de resultados de qualidade? - Como identificar e reduzir desigualdades a partir da complexidade e fragmentação do financiamento, orçamentação, implementação e prestação de contas das atividades dos diversos campos de atuação do sistema de saúde, cuja articulação e complementaridade são imprescindíveis para gerar impactos significativos sobre as condições de saúde da população?

- Como identificar e reduzir desigualdades sem o suporte político-institucional necessário para o desenvolvimento de práticas de tratamento e análise sistemática das informações se- toriais (e extra-setoriais relacionadas), e instituição de rotinas de acompanhamento, monitoramento e avaliação da situação de saúde e das estratégias e intervenções implementadas, para a alimentação e retroalimentação do processo decisório?

Ainda que não completamente desenhados, al guns caminhos para superar essas dificuldades, já esboçados nos espaços institucionais de formulação, gestão e/ou ação setorial, merecem destaque pelo potencial que carregam de promover a eqüidade na gestão do sistema:

a) a valorização da epidemiologia como conhecimento científico imprescindível à compreensão dos determinantes e riscos que condicionam o processo saúde-doença em cada local; como conjunto de métodos e técnicas relevantes para a identificação dos principais problemas que afligem a população e das prioridades nacionais, regionais e locais; enfim, como suporte básico ao planejamento, administração e avaliação do impacto de políticas, programas, ações e serviços;

b) a valorização da experiência cotidiana da população, dos usuários do sistema, dos profissionais de saúde, dos gestores locais, não apenas na avaliação e controle de suas ações e na definição de prioridades e estratégias para a gestão política da saúde, mas na identificação e qualificação permanente dos problemas, carências e lacunas na operação do sistema de saúde; c) a emergência de demandas estruturadas dos gestores do SUS das três esferas de governo por cooperação técnico-científica, e o desenvolvimento de parcerias com instituições acadêmicas para o aperfeiçoamento/qualificação de seus profissionais e para a eficiência de suas intervenções;

d) o redimensionamento da oferta de ações e serviços de saúde no território nacional, no contexto de um processo de regional ização da assistência à saúde, que visa aprofundar a descentralização e garantir a eqüidade no acesso dos cidadãos brasileiros a uma aten ção integral.

M uito há ainda a explorar neste debate. Fica, portanto, para o leitor o convite à reflexão sobre as capacidades que precisam ser desenvolvidas nos espaços de gestão descentralizada do sistema, para que em todas as unidades federativas possa se escolher, em um campo cada vez mais fértil de oportunidades reais, aquelas que melhor contribuam para o estabelecimento da eqüidade em saúde no Brasil. 


\section{Referências bibliográficas}

Araújo HE 2001. Desigualdades, mudanças demográficas recentes e perfil epidemiológico como variáveis políticas de saúde - uma análise regional, pp. 515-528. In B N egri \& G Giovanni (orgs.). Brasil: radiografia da saúde. Unicamp, São Paulo.

Brasil 2002. A O peracionalização da Emenda Constitucional n. 29. Relatório do seminário, com subsídios para o estabelecimento de diretrizes voltadas à aplicação e operacionalização da Emenda Constitucional n. 29. M inistério da Saúde, Subsecretaria de Assuntos Administrativos, Brasília.

Castel R 1998. As metamorfoses da questão social: uma crônica do salário. Editora Vozes, Petrópolis.

Chetre 2000. What is equity?, p. 4. In An area health service taking action to achieve health for all'. N ewsletter 1. Center for Health Equity, Training, Research and Evaluation. The University of New South Wales. School of Public Health \& Community M edicine, Austrália.

Duarte et al. 2002. Epidemiologia das desigualdades no Brasil. Organização Pan-Americana da Saúde, Brasília. 123pp.

Duarte CM R 2000. Eqüidade na legislação: um princípio do sistema de saúde brasileiro? Ciência e Saúde Coletiva 5(2): 443-463.

Escorel S 2001. Os dilemas da eqüidade em saúde: aspectos conceituais, 22 pp. Organização Pan-Americana da Saúde, Brasília. Disponível em </www.opas.org.br/ serviço/arquivos/sala3310>

Gentile M 2001. Promoção da saúde e município saudável. Vivere, São Paulo.

Kliksberg B 1998. Repensando o Estado para o desenvolvimento social: superando dogmas e convencionalismos. Cortez, São Paulo. (Coleção Questões da N ossa Época, v. 64).

Lucchese P, Cavalini L, Campos M R \& Garcia M 2002. Processo alocativo e redução de desigualdades regionais. Eqüidade na gestão do Sistema Ú nico de Saúde. Relatório de Pesquisa. Ministério da Saúde-Secretaria Executiva-Abrasco-Fiocruz-ENSP-D epartamento de Ciências Sociais (mimeo).

M ello Jorge M HP, Gotlieb SLD \& Laurentti R 2001. A saúde no Brasil: análise do período 1996 a 1999. Organização Pan-Americana da Saúde, Brasília.
Naciones Unidas 2000. Equidad, desarrollo y ciudadanía. Cepal, Chile.

Naciones U nidas 2001. La salud y el desarrollo sostenible, 7 pp. Consejo Económico y Social. Disponível em $<$ www.un.org/spanish/documents/esc/document. htm. Comisión sobre el Desarrollo Sostenible.E/CN . $17 / 2001 / P C / 6>$

Rosanvallon P 1998. A nova questão social: repensando o Estado Providência. Instituto Teotônio Vilela, Brasília.

Santos BS (org.) 2002. A globalização e as ciências sociais. Cortez Editora, São Paulo.

Santos BS 1998. Reinventar a democracia. Fundação M ário Soares-Gradiva Publicações, Lisboa. (Cadernos Democráticos, 4).

Sen AK 2001. Desigualdade reexaminada. Record. Rio de Janeiro. 301pp.

UN, United Nations 2000. Integrating environment and development in decision making, $16 \mathrm{pp}$. Agenda 21, Chapter 8. U nited N ations Division for Sustainable Development. Disponível em <www.un.org/esa/ sustdev/documents/agenda21>.

UNDP, United N ations Development Programme 2002. Human Development Report 2002. Deepening democracy in a fragmented world. Oxford University Press, N ova York. Disponível em <www.undp.org>.

Viana SM , Nunes A, Santos JRS \& Barata R 2001. M edindo as desigualdades em saúde no Brasil. Organização Pan-Americana da Saúde, Instituto de Pesquisa Econômica Aplicada, Brasília.

Vieira L 2001. Os argonautas da cidadania. Record, Rio deJaneiro.

Whitehead M 1992. The concepts and principles of equity in health. International Journal of $\mathrm{H}$ ealth Services 22:429-445.

Zaluar A 1997. Exclusão e políticas públicas: dilemas teóricos e alternativas políticas. Revista Brasileira de $\mathrm{Ci}$ ências Sociais 12(35):29-47.

Artigo apresentado em 23/4/2003

A provado em 20/5/2003

Versão final apresentada em 3/6/2003 